\title{
A Project Report on Features of PLC and its Different Modes of Communication
}

\author{
Rakshith Ramesh Iyer \\ Birla Institute of Technology Mesra, \\ India
}

\begin{abstract}
Twenty years back, machines were basic, and work in industries was, generally, manual in nature. Machines were intended to be physically controlled. Today, if individuals search for around them will discover numerous things have the control frameworks, which are important to compose the perplexing gadgets. The control framework is of essential significance for gadgets and machines in processing plants, airplane, vehicles, and even in some home gadgets. Today, it is hard for individuals to evade the utilization of control frameworks in the work place. Without mechanized control frameworks, industrial facilities face numerous issues, which would somehow or another be extremely elusive an answer for.
\end{abstract}

Keeping this in mind, The study is an attempt to understand the concept of PLC and its different modes of communication viz-a-viz wired and wireless. Wired communication includes RS485 and Profinet mode, while in Wireless communication IWLAN is used.

At present, wired communication is used by MANY MANUFACTURING INDUSTRIES. Wired communication is expensive and space consuming, so the industries should plan to divert themselves into wireless communication to meet the requirements of technological advancement as well as to embark into INDUSTRY 4.0.

\section{PLC}

A Programmable Logic Controller or PLC is a PC or machine used for modern mechanization. These controllers can robotize a specific system, machine work, or even an entire creation line. The PLC gets information from related sensors or data contraptions, shapes the data, and triggers yields reliant on pre-modified limits.

Contingent on the wellsprings of data and yields, a PLC can screen and record run-time data, for instance, machine effectiveness or working temperature, normally start and stop structures, produce cautions in the event that a machine breakdowns, to say the very least.

INPUT $=>$ PLC $=>$ OUTPUT

Programmable Logic Controllers are a flexible and robust control solution, adaptable to almost any application.

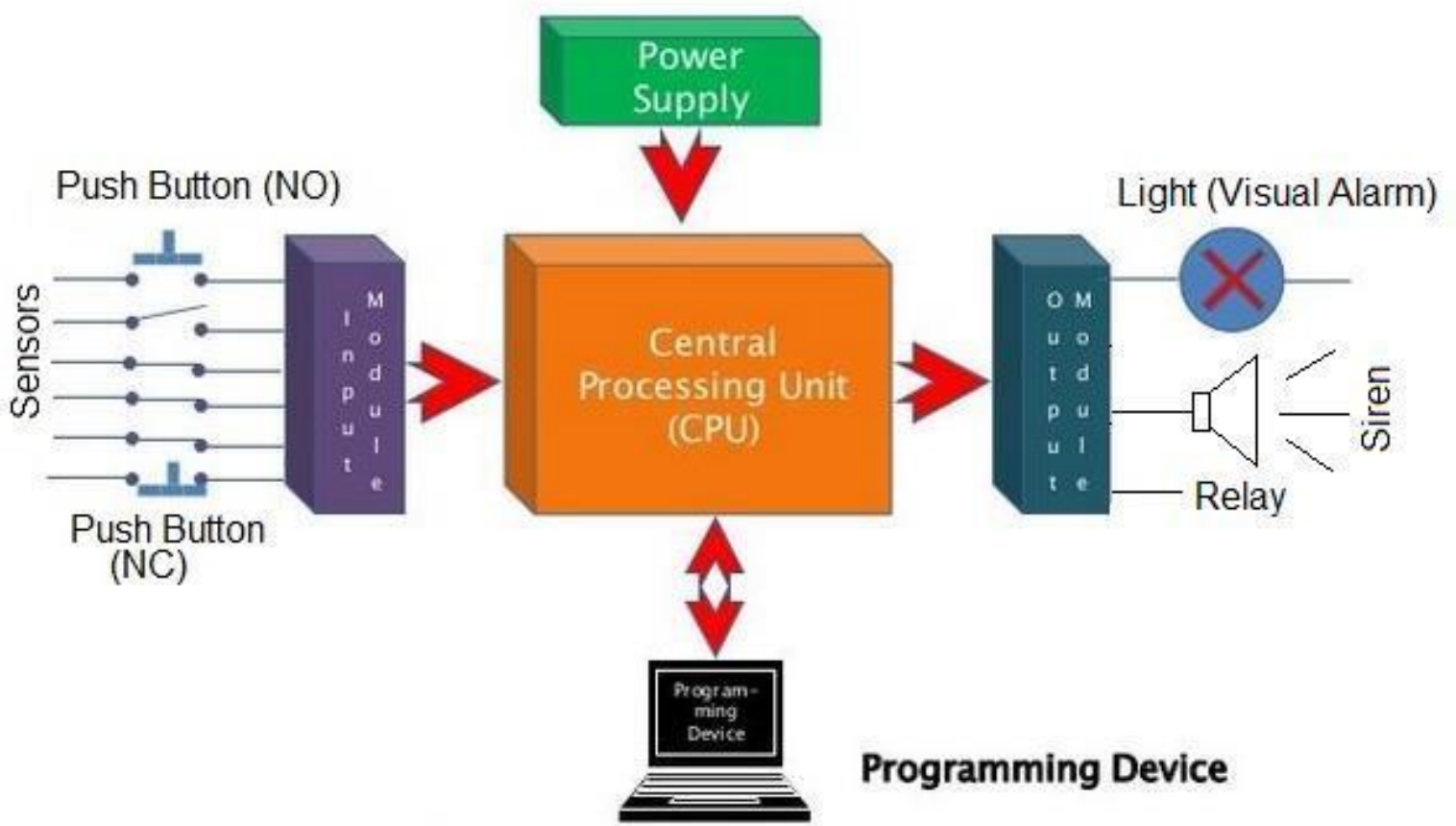

Fig 1 
There are a few key features that set PLCs apart from industrial PCs, microcontrollers, and other industrial control solutions:

- $\mathrm{I} / \mathrm{O}$ - The CPU is the spot the program data is taken care of and arranged anyway the information and yield modules are the ones that partner PLC to the rest of the machine; these $\mathrm{I} / \mathrm{O}$ modules offer information to the CPU and trigger unequivocal results. I/O can be either basic or automated; input contraptions may join sensors, switches, and meters, while yields may fuse moves, lights, valves, and drives.

- Communications - despite data and yield devices, a PLC may in like manner need to interface with various kinds of systems; for example, customers ought to convey application data recorded by the PLC to an authoritative control and data acquiring (SCADA) structure, which screens various related devices. PLCs offer an extent of ports and correspondence shows to ensure that the PLC can talk with these various structures.

- HMI - So as to speak with the PLC consistently, customers need a HMI, or Human Machine Interface. These director interfaces can be clear introductions, with a book readout and keypad, or tremendous touchscreen sheets more like client devices, yet regardless, they enable customers to review and data information to the PLC persistently.

\section{CERTAIN FEATURES INCLUDE: -}

- Low power usage

- Human Safety

- Small in size

- Fast Trouble shooting capability

- Easy to maintain

- Human Machine Interface

- Easy programming

- High productivity

- Superior quality

$>$ PLC BASICS

- Kinds of PLC:

$\checkmark$ Monoprocessor

$\checkmark$ Fieldbus association

- Modular PLC:

$\checkmark$ Modular development (backplane)

$\checkmark$ One- or multiprocessor framework

$\checkmark$ Fieldbus and LAN association

- Soft-PLC:

$\checkmark$ Windows NT or CE-based robotisation products

$\checkmark$ Direct utilization of CPU or co-processors

- CLASSIFICATION BASED ON SPEED AND SIZE.

- Small - $128 \mathrm{I} / \mathrm{O}, 2 \mathrm{~Kb}$

- Medium - $2048 \mathrm{I} / \mathrm{O}, 32 \mathrm{~Kb}$

- Large $-8192 \mathrm{I} / \mathrm{O}, 750 \mathrm{~Kb}$

\section{HARDWARE}

- Chassis/Rack- Divided into Two type-

9 slots and 18 slots.

Further the Rack is classified into

Active Backplane - Used in S7-400

Passive Backplane - Used in S7-300

- Power Supply: 220VAC UPS or Battery for RAM

- Modes - Programming mode, stop mode, run mode, Reset mode

- Signal Modules -

INPUT- Digital (Push button, Emergency Proximity) Analog (Thermocouple, Flow pressure transmitter) Variable Frequency (Encoder, Strain Gauge, Flow meter)

OUTPUT- Digital (Lamp, LED, Solenoid valves) Analog (Servo valve, Drives)

- Communication - HMI, Drives, PLC, Third Party

Communication Protocols: -

$\checkmark$ Multipoint Interface- 32 nodes, Speed-187.5Kbps.

$\checkmark$ Profibus DP- 126 nodes, Speed- 1.5Mbps to $12 \mathrm{Mbps}$.

$\checkmark$ Industrial Ethernet- 1024 nodes, Speed- 100Mbps.

> PROGRAMMING

- Ladder Diagram (Commonly Used)

- Statement list (Least Memory in CPU)

- Function Block Diagram

D RACK CONNECTIONS

Slot 1- Power Supply

Slot 2- CPU

Slot 3 - Interface Module or Empty in S7-300

Slot 4 - Signal or Function

\section{> PROGRAM STRUCTURE}

For S7 PLC - Comprises of Organisation Block (OB1), Functions (FC1), Function Block (FB4), Data Block (DB4) and System Block (SFC, SFB, SDB).

\section{ORGANISATION BLOCK (OB) DETAILS}

The Organisation Block1 is automatically called for S7OB- 30 to 38 (cyclic interpretation).

Error OB- 80 to 87 , OB- 121-122

Hardware Interruption OB- 40 to 47

Time Delay OB- 20 to 23 and OB-10 to 17

\section{INSTRUCTIONS IN PLC INCLUDES}

- Bit level- Comprises of Normally open, normally closed, invert power, Midline, reset level, Set, R-S flipflop, S-R flip-flop, negative and positive RLO edge.

- Timer or Counter- On-Delay, Off-Delay, Pulse, set storage, Extend pulses. Counter Types are (Counter ID, Counter Up, Counter Down, set input, reset input, Current value.)

- Comparison like Greater than, lesser than, equal to, greater or equal to and lesser or equal to.

- Conversion

- Mathematical. 
* PLCs are used in lots of applications:

- Parts-machining

- Packaging machines

- Material dealing with

- Automatic get together

- Petrochemical / Chemical

- Mining

- And by and large, any sort of utility that calls electric controls can utilize a PLC.

> PLCBRANDS

- $\mathrm{ABB}$

- Allen-Bradley

- Siemens

- Honeywell
- Mitsubishi

- Yokogawa

- Toshiba

- General Electric

- Omron

- Schneider Automation

- Reliance

- Hitachi

- Modicon

At present numerous brands and sorts of PLC are broadly utilized in ventures going from low-end to top of the line. Here are a few brands and sorts of PLC that are broadly utilized in industry:

\begin{tabular}{|c|c|c|c|c|}
\hline SR NO & BRAND & SOFTWARE USED & TYPE & TYPE OF PLC \\
\hline 1] & SIEMENS & SIMATIC & $\begin{array}{c}\text { MICRO PLC } \\
\text { MODULAR PLC }\end{array}$ & $\begin{array}{c}\text { 1] S7- } 200 \\
\text { 2] } \mathrm{S} 7-1200 \\
\text { 3] } \mathrm{S} 5-1150\end{array}$ \\
\hline 2] & ALLEN BRADLEY & RS LOGIX & $\begin{array}{c}\text { LOGIX -5 } \\
\text { LOGIX-500 } \\
\text { LOGIX-5000 }\end{array}$ & $\begin{array}{l}\text { PLC-5, SLC-500 } \\
\text { 1] CONTROL LOGIX } \\
\text { 2] FLEX LOGIX }\end{array}$ \\
\hline 3] & OMRON & CX PROGRAMMER & $\begin{array}{l}\text { MICRO PLC } \\
\text { BASIC PLC } \\
\text { MODULAR PLC }\end{array}$ & $\begin{array}{l}\text { 1] CPMIA } \\
\text { 2] CPIL } \\
\text { 3] CJIM } \\
\text { 4] CJIH }\end{array}$ \\
\hline 4] & SCHNEIDER & $\begin{array}{c}\text { PL-7 } \\
\text { PROWORX } 32\end{array}$ & $\begin{array}{c}\text { MICRO PLC } \\
\text { MACHINE } \\
\text { SMART RELAY } \\
\text { PROCESS CONTROL }\end{array}$ & $\begin{array}{c}\text { MODICON M340 } \\
\text { MODICON } \\
\text { PREMIUM } \\
\text { ZELIO }\end{array}$ \\
\hline 5] & MITSUBISHI & MELSOFT SERIES & $\begin{array}{c}\text { COMPACT } \\
\text { MODULAR } \\
\text { PROCESS CONTROL }\end{array}$ & $\begin{array}{l}\text { 1] MELSEC FX3UG } \\
\text { 2] MELSEC FX3G } \\
\text { 3] Q SERIES }\end{array}$ \\
\hline
\end{tabular}

Table 1

\section{RS485 PROTOCOL}

\section{What is an RS-485 network?}

RS-485 is utilized as the physical layer hidden numerous norm and exclusive mechanization conventions used to execute mechanical control frameworks, including the most well-known forms of Modbus and Profibus. These are utilized in programmable rationale regulators. RS-485 permits different gadgets for example up to 32 to impart at half on a solitary pair of wires, in addition to a ground wire, at separations up to 1200 meters or 4000 feet.

\section{- How does the hardware work?}

Information is sent differentially on two wires turned together, referred to as a "bent pair." The properties of differential signs give high noise immunity and significant distance abilities. A 485 system can be designed two different ways, "two-wire" or "four-wire." In a "two-wire" organize the transmitter and recipient of every gadget are associated with a turned pair. "Four-wire" systems have one ace port with the transmitter associated with each of the "slave" collectors on one contorted pair. The "slave" transmitters are totally associated with the "ace" recipient on a second turned pair. In either arrangement, gadgets are addressable, permitting every hub to be conveyed to autonomously. Some RS-485 equipment handles this consequently. In different cases, the 485-gadget programming must utilize a control line to deal with the driver. This is an outcome of tri-expressing. The Tri-State driver resembles a one directional switch: When the Enable is on $(\mathrm{E}=1)$ it moves the contribution to the yield. The drivers have a postponement between the finish of a transmission and when the driver is tri-expressed. This pivot delay is a significant piece of a two-wire organize in light of the fact that during that time no different transmissions can happen which isn't the situation in a fourwire setup. An ideal delay is the length of one character at the current baud rate for example $1 \mathrm{~ms}$ at 9600 baud. The gadget producer ought to have the option to gracefully data on the postponement for their items.

\section{Two wire or four wire?}

Two-wire 485 systems have the benefit of lower wiring costs and the capacity for hubs to talk among themselves. On the drawback, two-wire mode is constrained to half-duplex and expects consideration regarding pivot delay. Four-wire systems permit full-duplex activity, however are restricted to ace slave circumstances 
for example an "ace" hub demands data from singular "slave" hubs. "Slave" hubs can't speak with one another.

How accomplishes the product work? The 485 programming handles tending to, pivot delay, and potentially the driver tri-state highlights of 485 . To an extreme or too little pivot postponement can cause investigating fits, and deferral ought to be an element of baud rate interfacing a multidrop 485 system. The EIA RS485 Specification names the information wires "An" and "B", yet numerous makers name their wires "+" and "-. ". The "- " wire ought to be associated with the "A" line, and the "+" wire to the "B" line. Switching the extremity won't harm a 485 gadget, yet it won't impart. Utilization of sign ground is fundamental. While a differential sign doesn't require a sign ground to impart, the ground wire fills a significant need. Over a separation of hundreds or thousands of feet there can be exceptionally huge contrasts in the voltage level of ground. RS-485 systems can normally keep up right information with a distinction of -7 to +12 Volts. In the event that the grounds vary more than that sum, information will be lost and regularly the port itself will be harmed. The capacity of the sign ground wire is to tie the sign ground of every one of the hubs to one shared belief. In any case, if the distinction in signal grounds is excessively incredible, further consideration is essential.

- Before focusing more on Profinet we take a look on two important comparisons associated with it:

$\checkmark$ Ethernet and Industrial Ethernet

$\checkmark$ EtherNet/IP and Profinet

\section{Ethernet and Industrial Ethernet}

Ethernet is the gathering of neighbourhood (LAN) items secured by IEEE 802.3 which is a gathering of Institute of Electrical and Electronics Engineers (IEEE) norms that predefine the physical layer and information interface layer of a wired Ethernet media get to control. These norms additionally portray the standards for designing an Ethernet system and how the components of the system work with each other. Ethernet is the worldwide norm for an arrangement of wires and links to join numerous PCs, gadgets, machines, and so forth, over an association's single system so all the PCs can speak with each other.

Then again, Industrial Ethernet is an Ethernet applied to a modern setting, which regularly requires more tough connectors, links, and in particular better determinism. So as to accomplish better determinism, modern Ethernet utilizes specific conventions related to Ethernet.

The more famous modern Ethernet conventions are PROFINET, EtherNet/IP, EtherCAT, SERCOS III, and POWERLINK.

With current Ethernet, data transmission rates stretch out from $10 \mathrm{Mbps}$ to $1 \mathrm{Gbps}$. In any case, $100 \mathrm{Mbps}$ is the most notable speed used in mechanical Ethernet applications. Determinism is a significant factor when characterizing Industrial Ethernet and isolating it from Ethernet. Standard Ethernet isn't deterministic all alone. They need parcels of information to be sent and gotten at explicit occasions, and they need an assurance that information will be conveyed every single time. This is on the grounds that lost information or a deferral of information between gear in a mechanical setting can end in misfortune-like a significant blemish in the creation procedure, for example. Each association needs to survey their requirements and decide their decision of Ethernet arrangement.

\section{EtherNet/IP AND PROFINET}

When it comes to Ethernet Protocols EtherNet/IP and Profinet are clear leaders. Neither of them is as deterministic as Profibus or DeviceNet. Rockwell automation promotes EtherNet/IP which is based on CIP (Common Industrial Protocol) whereas Siemens promotes Profinet which is built on Profibus model. Both are open networks which are backed by extensive communities. Ethernet/IP is managed by ODVA (Open Device Vendor Association) whereas Profinet by PI North America. Profinet is faster because it is built on Profibus standard.

Profinet RT is a fast solution deployed with standard hardware. EtherNet/IP is more interoperable and built on object-oriented programming and is highly standardised.

\section{PROFINET}

PROFINET is a system to trade information among regulators and gadgets. Regulators could be PLC, DCS (Distributed Control Systems), or PAC (Programmable Automation Controllers). Gadgets could be I/O squares, vision frameworks, RFID per users, drives, process instruments, intermediaries, or significantly different regulators. PROFINET is the correspondence standard for automation of PROFIBUS and PROFINET International (PI).

PROFINET trades information rapidly and deterministically. Required rates differ contingent upon the application; process instruments update in many milliseconds, manufacturing plant gadgets have a lot faster updates, and movement control synchronization is requesting. Determinism implies the messages show up when they should.

We see that Competing conventions are not as quick, deterministic, or shut systems. For instance, Modbus TCP utilizes TCP (Transmission Control Protocol) which necessitates that a virtual association is set up between the two gadgets; at that point messages must go through the TCP/IP stack.

PROFINET trades information including quality and resource the executive's data. PROFINET trades information in a predefined course of action. It can mastermind the information to such an extent that all the boundaries are consistently in a similar spot, permitting gadgets to be changed starting with one merchant then onto 
the next with no client association required. Procedure instruments, drives, vitality estimations, and numerous other basic gadgets have what we call Application Profiles to achieve this.

Uses of PROFINET:

- Easy to Use for industrial purposes: High plant availability, fast and efficient automation, minimizes the cost of installation and commissioning.

- Flexible Networking choice: Saves on costly custom arrangements and empowers remote correspondence with WLAN and Bluetooth.

- Combined Diagnostics: Provides significant data in regards to the status of gadgets and system, including a presentation of the system geography.

- Safety: The likelihood to utilize a similar link for standard and wellbeing related correspondence helps in putting something aside for gadgets, designing, and arrangement.

- Availability: The ideas for media and framework excess increment the plant accessibility fundamentally.

- Energy advancement: The utilization of Energy in a mechanization framework can be estimated utilizing a normalized strategy and can be constrained by specifically turning capacities on and off without extra equipment.

\section{PROFINET I/O System}

PROFINET IO follows the Provider/Consumer model for information trade. Designing a PROFINET IO framework has a similar look and feel as in PROFIBUS.

IO regulator: This is ordinarily the programmable rationale regulator (PLC) on which the mechanization program runs. This is equivalent to a class 1 ace in PROFIBUS. The IO regulator gives yield information to the arranged IO gadgets as a supplier and is the purchaser of information of IO gadgets.

IO gadget: An IO gadget is a conveyed I/O field gadget that is associated with at least one IO regulators by means of PROFINET IO. It is practically identical to the capacity of a slave in PROFIBUS. The IO gadget is the supplier of information and the customer of yield information.

IO Supervisor: This can be a Programming Device (PD), (PC), or human machine interface (HMI) gadget for authorizing or symptomatic purposes and compares to a class 2 ace in PROFIBUS.

\section{- General Structure of Data Cable}

By and large, information organizes links include various structures; the individual parts in them satisfy the accompanying capacities:

- Sheath: insurance against concoction media or mechanical impacts.

- Copper twisting: security against outer EMC impacts.
- Foil screening as generally speaking screening: security against outer EMC impacts, insurance against crosstalk for two information links.

- Foil screening as individual pair screening: screening of the individual centre sets from each other.

- Fast Connect sheath: sheath and protecting are sliced to the correct length for speedy association with the connector.

- Core protection: liable for the transmission qualities, e. g. limits or trademark impedance

- Conductor: electrical association for information and force.

\section{$>$ PROFINET Cable}

The PROFINET framework is indicated universally in IEC 61918 for cabling inside and between computerization islands and creation islands. The particular framework for PROFINET cabling and association arrangements is normalized thusly in IEC 61784-5-3. This applies for copper-based and fiber optic transmission media and remote transmission. The 'PROFINET Cabling and Interconnection Technology Guideline' is made by a working gathering inside the PNO. It generally indicates three link types for copper transmitters - for 2-pair and 4pair links. This detail thusly characterizes the specific structure and the mechanical and electrical prerequisites.

- Type A: for fixed establishment, no flexing after establishment.

- Type B: for adaptable establishment, intermittent flexing of the link following establishment.

- Type C: for uncommon necessities, for example, use in power chains, twist applications, and so on.

- Two link types are characterized for half breed links (information combines and control centers).

- Type B: for adaptable establishment, incidental flexing of the link following establishment, and vibrations

- Type C: for exceptional applications, for example, use in power chains, twist applications, and so on.

At first, PROFINET was determined distinctly for transmission of information at $100 \mathrm{Mbit} / \mathrm{s}$ with 2-pair Cat.5 links. Notwithstanding, so as to make this Industrial Ethernet framework considerably more effective, 4-pair links for transmission of information at up to $10 \mathrm{Gbit} / \mathrm{s}$ have likewise been normalized since 2013 .

Notwithstanding the links and connectors for information transmission, it is the predefined to utilize connectors for the force flexibly. One case of this is the M12 A-coded connector that is accessible in both a connector plan and a female structure. The M12 connector compares to IEC 60512 and is characterized as either a 4pin or 5-pin structure.

For the purpose of connecting devices it is recommended to use, M12 flush-type connectors with integrated stranded wire for PCB connection. Also use of field mountable connectors for rapid configuration of 
individual cable lengths for M8 and M12 sensor/actuator cables is advised.

To perform fast cabling of sensors and actuators in the field a far reaching scope of over shaped links with M8, M12 and valve connector associations can be utilized. Signal statuses can be checked effortlessly by methods for the sensor/actuator link structures highlighting LEDs. Links with a screened wire likewise agree to the prerequisites concerning expanded EMC similarity.

\section{Types of Cable and their Specification}

We take a look at some of the cables used in Profinet prepared by Lapp group, and their specifications

- PROFINET Type A 2-pair:

Cat 5 cables for fixed installation

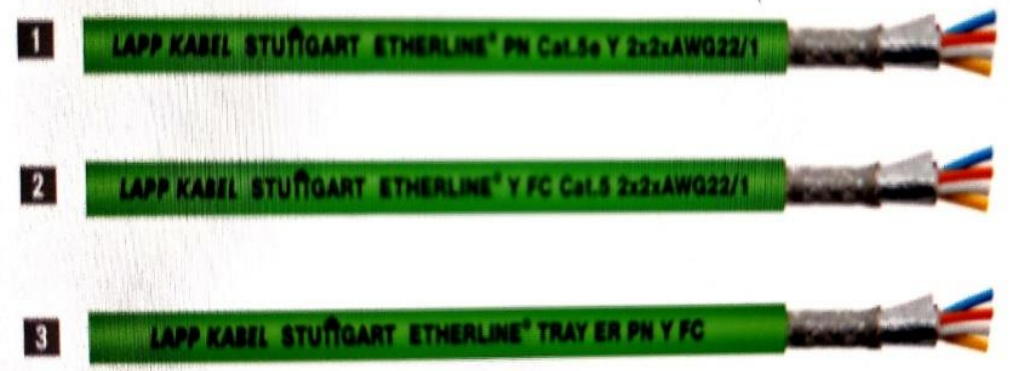

Fig 2

\begin{tabular}{|c|c|c|c|}
\hline FEATURES & ETHERLINE PN Cat 5 EY & ETHERLINE Y FC Cat 5 & $\begin{array}{c}\text { ETHERLINE TRAY PN Y } \\
\text { FC }\end{array}$ \\
\hline APPLICATION AREAS & $\begin{array}{l}\text { 1] FOR FIXED } \\
\text { INSTALLATION } \\
\text { BETWEEN MACHINERY } \\
\text { AND PLANTS. } \\
\text { 2] FOR DRY OR DAMP } \\
\text { ROOMS. }\end{array}$ & $\begin{array}{l}\text { 1] SUITABLE FOR } \\
\text { OUTDOOR. } \\
\text { 2] FOR FIXED } \\
\text { INSTALLATION } \\
\text { BETWEEN MACHINERY } \\
\text { AND PLANTS. }\end{array}$ & $\begin{array}{l}\text { 1] 600V RATING FOR LIVE } \\
\text { CABLE INSTALLATION. } \\
\text { 2] FOR INSTALLATION } \\
\text { BETWEEN MACHINERY } \\
\text { AND PLANTS. }\end{array}$ \\
\hline PROPERTIES & $\begin{array}{c}\text { 1] FLAME RETARDANT } \\
\text { ACCORDING TO IEC AND } \\
\text { VW-1 ACCORDING TO UL- } \\
1581 .\end{array}$ & $\begin{array}{c}\text { 1] AWM STYLE } \\
\text { 2] FLAME RETARDANT } \\
\text { ACCORDING TO IEC AND } \\
\text { VW-1 ACCORDING TO UL- } \\
1581 .\end{array}$ & $\begin{array}{c}\text { 1] FLAME RETARDANT } \\
\text { ACCORDING TO IEC AND } \\
\text { VW-1 ACCORDING TO UL- } \\
\text { 1581. } \\
\text { 2] UV RESISTANT } \\
\text { ACCORDING TO UL-1581. }\end{array}$ \\
\hline TEMPERATURE RANGE & $\begin{array}{l}\text { 1] FLEXING- }(-5 \mathrm{C}) \text { TO } \\
+50 \mathrm{C} \text {. } \\
\text { 2] FIXED INSTALLATION- } \\
(-40 \mathrm{C}) \text { UP TO }(+75 \mathrm{C})\end{array}$ & $\begin{array}{l}\text { 1] FLEXING- }(-20 \mathrm{C}) \text { TO } \\
+60 \mathrm{C} . \\
\text { 2] FIXED INSTALLATION- } \\
(-40 \mathrm{C}) \text { UP TO }(+80 \mathrm{C})\end{array}$ & $\begin{array}{l}\text { 1] FLEXING- }(-20 \mathrm{C}) \mathrm{TO} \\
+60 \mathrm{C} . \\
\text { 2] FIXED INSTALLATION- } \\
(-40 \mathrm{C}) \text { UP TO }(+80 \mathrm{C})\end{array}$ \\
\hline BENDING RADIUS & $\begin{array}{c}\text { FLEXING- 7.5x CABLE } \\
\text { DIAMETER } \\
\text { FIXED INSTALLATION- 3x } \\
\text { CABLE DIAMETER. }\end{array}$ & $\begin{array}{l}\text { FLEXING- 15x CABLE } \\
\text { DIAMETER } \\
\text { FIXED INSTALLATION- } \\
\text { 10x CABLE DIAMETER. }\end{array}$ & $\begin{array}{l}\text { FLEXING- 15x CABLE } \\
\text { DIAMETER } \\
\text { FIXED INSTALLATION- } \\
\text { 10x CABLE DIAMETER. }\end{array}$ \\
\hline
\end{tabular}


- PROFINET Type B 2-pair:

Cat 5 cables for flexible use

\section{a}

Fig 3

\begin{tabular}{|c|c|c|c|}
\hline FEATURES & $\begin{array}{l}\text { ETHERLINE PN Cat 5Y } \\
\text { FLEX FC }\end{array}$ & $\begin{array}{c}\text { ETHERLINE PN Cat } 5 \\
\text { FRNC FLEX }\end{array}$ & $\begin{array}{l}\text { ETHERLINE MARINE } \\
\text { FRNC }\end{array}$ \\
\hline APPLICATION AREAS & $\begin{array}{c}\text { 1] FOR FIXED } \\
\text { INSTALLATION } \\
\text { BETWEEN MACHINERY } \\
\text { AND PLANTS. } \\
\text { 2] FOR DRY OR DAMP } \\
\text { ROOMS. } \\
\text { 3] ALSO SUITABLE FOR } \\
\text { OUTDOOR APPLICATION. }\end{array}$ & $\begin{array}{l}\text { 1] SUITABLE FOR } \\
\text { OUTDOOR. } \\
\text { 2] FOR FIXED } \\
\text { INSTALLATION } \\
\text { BETWEEN MACHINERY } \\
\text { AND PLANTS. }\end{array}$ & $\begin{array}{l}\text { 1] SUITABLE FOR } \\
\text { OUTDOOR. } \\
\text { 2] FOR INSTALLATION } \\
\text { BETWEEN MACHINERY } \\
\text { AND PLANTS. }\end{array}$ \\
\hline PROPERTIES & $\begin{array}{c}\text { 1] FLAME RETARDANT } \\
\text { ACCORDING TO IEC AND } \\
\text { VW-1 ACCORDING TO UL- } \\
1581 .\end{array}$ & $\begin{array}{l}\text { 1] FLAME RETARDANT } \\
\text { ACCORDING TO IEC AND } \\
\text { VW-1 ACCORDING TO UL- } \\
1581 .\end{array}$ & $\begin{array}{c}\text { 1] FLAME RETARDANT } \\
\text { ACCORDING TO IEC AND } \\
\text { VW-1 ACCORDING TO UL- } \\
1581 . \\
\text { 2] HALOGEN FREE } \\
\text { ACCORDING TO IEC. }\end{array}$ \\
\hline TEMPERATURE RANGE & $\begin{array}{l}\text { 1] FLEXING- }(-20 \mathrm{C}) \mathrm{TO} \\
\text { +60C. } \\
\text { 2] FIXED INSTALLATION- } \\
(-40 \mathrm{C}) \text { UP TO }(+80 \mathrm{C})\end{array}$ & $\begin{array}{l}\text { 1] FLEXING- }(-25 \mathrm{C}) \mathrm{TO} \\
+80 \mathrm{C} \text {. } \\
\text { 2] FIXED INSTALLATION- } \\
(-25 \mathrm{C}) \text { UP TO }(+80 \mathrm{C})\end{array}$ & $\begin{array}{l}\text { 1] FLEXING- }(-40 \mathrm{C}) \mathrm{TO} \\
+105 \mathrm{C} \text {. } \\
\text { 2] FIXED INSTALLATION- } \\
\text { (-30C) UP TO }(+105 \mathrm{C})\end{array}$ \\
\hline BENDING RADIUS & $\begin{array}{l}\text { FLEXING- 15x CABLE } \\
\text { DIAMETER } \\
\text { FIXED INSTALLATION- } \\
\text { 10x CABLE DIAMETER. }\end{array}$ & $\begin{array}{c}\text { FLEXING- 8x CABLE } \\
\text { DIAMETER } \\
\text { FIXED INSTALLATION- 4x } \\
\text { CABLE DIAMETER. }\end{array}$ & $\begin{array}{l}\text { FLEXING- 15x CABLE } \\
\text { DIAMETER } \\
\text { FIXED INSTALLATION- } \\
\text { 10x CABLE DIAMETER. }\end{array}$ \\
\hline
\end{tabular}


- PROFINET Type C 2-pair:

Cat 5 cables for special use

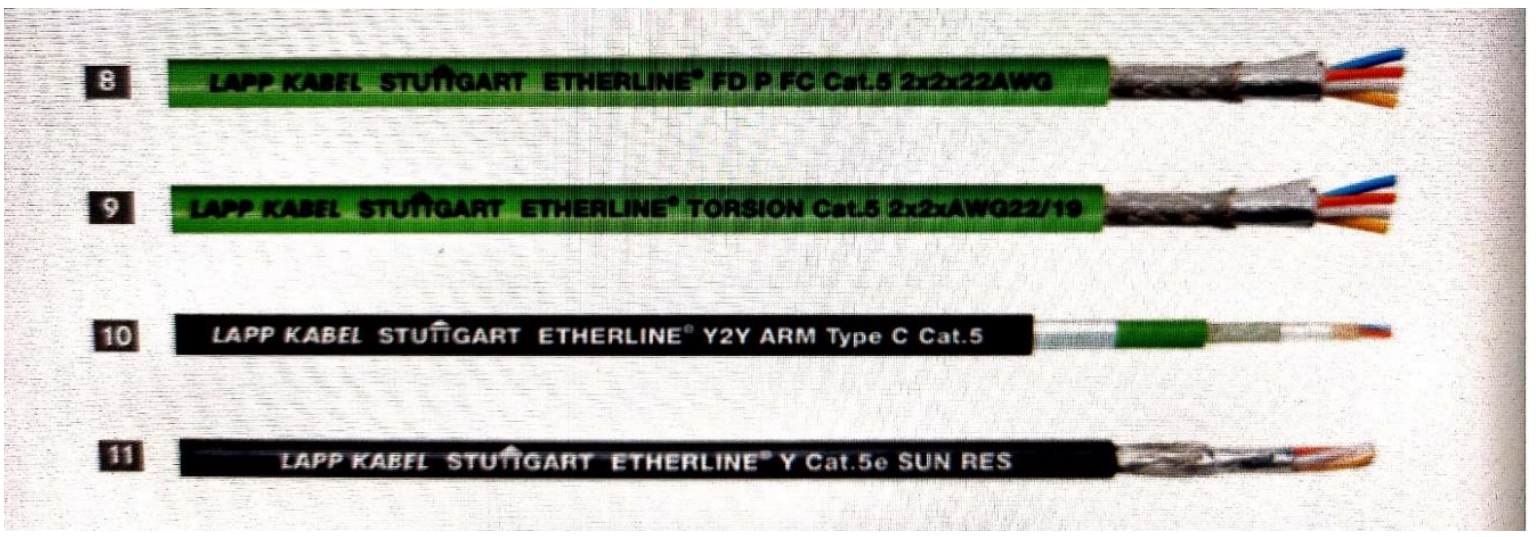

Fig 4

\begin{tabular}{|c|c|c|c|}
\hline FEATURES & $\begin{array}{l}\text { ETHERLINE FD P FC CAT } \\
5\end{array}$ & $\begin{array}{l}\text { ETHERLINE TORSION } \\
\text { CAT } 5\end{array}$ & ETHERLINE CAT 5 ARM \\
\hline APPLICATION AREAS & $\begin{array}{l}\text { 1] WIRING OF } \\
\text { MACHINERY AND } \\
\text { DEVICES. } \\
\text { 2] LARGELY RESISTANT } \\
\text { TO OIL AND GREASE. } \\
\text { 3] FOR HIGHLY FLEXIBLE } \\
\text { APPLICATION. }\end{array}$ & $\begin{array}{l}\text { 1] LARGELY RESISTANT } \\
\text { TO OIL AND GREASE. } \\
\text { 2] WIRING OF } \\
\text { MACHINERY AND } \\
\text { DEVICES AND CONTROL } \\
\text { CABINETS. }\end{array}$ & $\begin{array}{l}\text { 1] SUITABLE FOR } \\
\text { OUTDOOR. } \\
\text { 2] CAN BE USED IN DRY } \\
\text { OR DAMP ROOM. }\end{array}$ \\
\hline PROPERTIES & $\begin{array}{l}\text { 1] FLAME RETARDANT } \\
\text { ACCORDING TO IEC. } \\
\text { 2] HALOGEN FREE } \\
\text { ACCORDING TO VDE. }\end{array}$ & $\begin{array}{c}\text { 1] FLAME RETARDANT } \\
\text { ACCORDING TO IEC AND } \\
\text { VW-1 ACCORDING TO UL- } \\
\text { 1581. } \\
\text { 2] HALOGEN FREE } \\
\text { ACCORDING TO VDE. }\end{array}$ & $\begin{array}{l}\text { 1] UV RESISTANT } \\
\text { 2] HYDROLYSIS } \\
\text { RESISTANT. }\end{array}$ \\
\hline TEMPERATURE RANGE & $\begin{array}{l}\text { 1] FLEXING- }(-20 \mathrm{C}) \mathrm{TO} \\
\text { +60C. } \\
\text { 2] FIXED INSTALLATION- } \\
(-30 \mathrm{C}) \text { UP TO }(+70 \mathrm{C})\end{array}$ & $\begin{array}{l}\text { 1] FLEXING- }(-40 \mathrm{C}) \mathrm{TO} \\
+80 \mathrm{C}\end{array}$ & $\begin{array}{l}\text { 1] FLEXING- }(-20 \mathrm{C}) \mathrm{TO} \\
+60 \mathrm{C} \text {. } \\
\text { 2] FIXED INSTALLATION- } \\
(-40 \mathrm{C}) \text { UP TO }(+70 \mathrm{C})\end{array}$ \\
\hline BENDING RADIUS & $\begin{array}{c}\text { FLEXING- 8x CABLE } \\
\text { DIAMETER }\end{array}$ & $\begin{array}{l}\text { FLEXING- 8x CABLE } \\
\text { DIAMETER }\end{array}$ & $\begin{array}{c}\text { FLEXING- 15x CABLE } \\
\text { DIAMETER } \\
\text { FIXED INSTALLATION- } \\
\text { 10x CABLE DIAMETER. }\end{array}$ \\
\hline
\end{tabular}

- PROFINET Type A 4-pair:

Cat $6 \mathrm{~A}$ cables for fixed installation

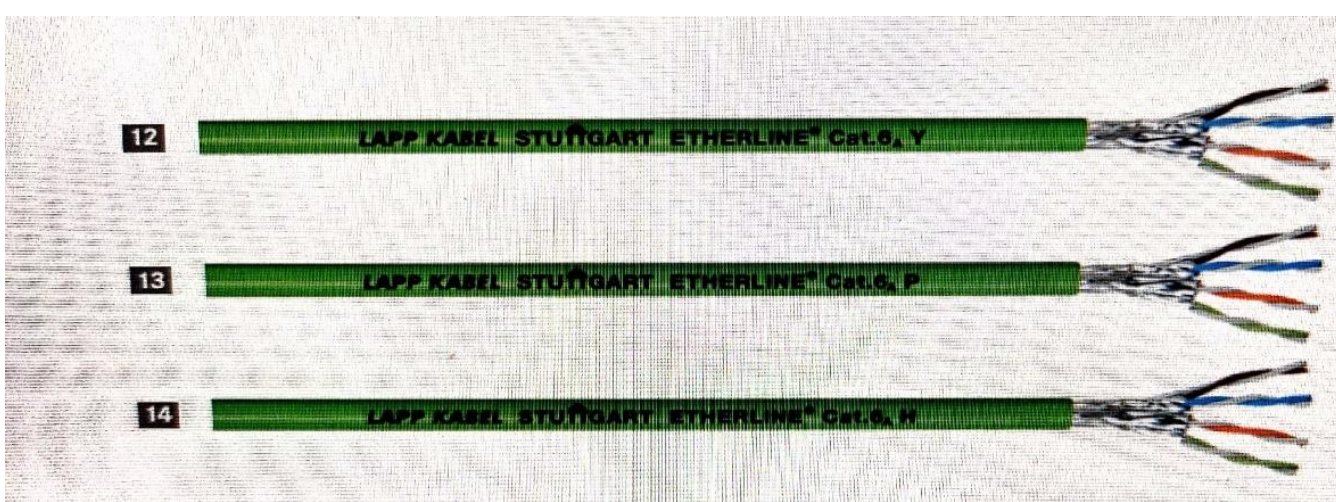

Fig 5 
ISSN No:-2456-2165

\begin{tabular}{|c|c|c|c|}
\hline FEATURES & ETHERLINE CAT 6A Y & ETHERLINE CAT 6A P & ETHERLINE CAT 6A H \\
\hline APPLICATION AREAS & $\begin{array}{l}\text { 1] FOR FIXED } \\
\text { INSTALLATION OF } \\
\text { MACHINERY AND } \\
\text { DEVICES. } \\
\text { 2] INSTALLATION ON } \\
\text { CLOSED CABLE } \\
\text { CIRCUITS. }\end{array}$ & $\begin{array}{l}\text { 1] CAN BE USED IN DRY } \\
\text { OR DAMP ROOM. } \\
\text { 2] FOR MORE } \\
\text { DEMANDING } \\
\text { MECHANICAL } \\
\text { REQUIREMENTS. }\end{array}$ & $\begin{array}{l}\text { 1] WHERE ABSENCE OF } \\
\text { HALOGEN IS REQUIRED. } \\
\text { 2] CAN BE USED IN DRY } \\
\text { OR DAMP ROOM. }\end{array}$ \\
\hline PROPERTIES & $\begin{array}{c}\text { 1] OIL RESISTANT } \\
\text { ACCORDING TO UL. } \\
\text { 2] UV RESISTANT } \\
\text { ACCORDING TO UL. }\end{array}$ & $\begin{array}{l}\text { 1] OIL RESISTANT } \\
\text { ACCORDING TO UL. } \\
\text { 2] HALOGEN FREE } \\
\text { ACCORDING TO VDE. }\end{array}$ & $\begin{array}{l}\text { 1] FLAME RETARDANT } \\
\text { ACCORDING TO IEC. } \\
\text { 2] HALOGEN FREE } \\
\text { ACCORDING TO VDE. }\end{array}$ \\
\hline TEMPERATURE RANGE & $\begin{array}{l}\text { 2] FIXED INSTALLATION- } \\
(-40 \mathrm{C}) \text { UP TO }(+80 \mathrm{C})\end{array}$ & $\begin{array}{l}\text { 1] FIXED INSTALLATION } \\
-(-40 \mathrm{C}) \mathrm{TO}+80 \mathrm{C} .\end{array}$ & $\begin{array}{l}\text { 2] FIXED INSTALLATION- } \\
(-25 \mathrm{C}) \text { UP TO }(+80 \mathrm{C})\end{array}$ \\
\hline BENDING RADIUS & $\begin{array}{l}\text { FIXED INSTALLATION - } \\
\text { 10x CABLE DIAMETER }\end{array}$ & $\begin{array}{c}\text { FIXED INSTALLATION - } \\
\text { 10x CABLE DIAMETER }\end{array}$ & $\begin{array}{l}\text { FIXED INSTALLATION- } \\
\text { 10x CABLE DIAMETER. }\end{array}$ \\
\hline
\end{tabular}

- PROFINET Type A 4-pair:

Cat 7 cables for fixed installation

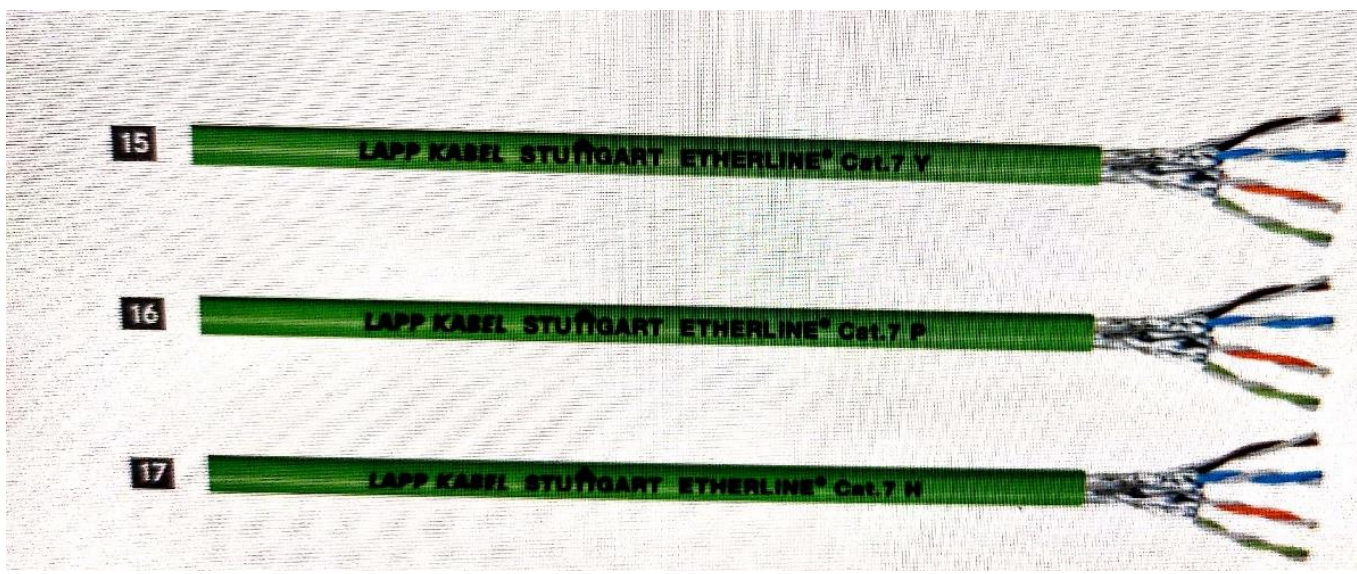

Fig 6

\begin{tabular}{|c|c|c|c|}
\hline FEATURES & ETHERLINE CAT 7 Y & ETHERLINE CAT $7 \mathrm{P}$ & ETHERLINE CAT $7 \mathrm{H}$ \\
\hline APPLICATION AREAS & $\begin{array}{l}\text { 1] FOR FIXED } \\
\text { INSTALLATION OF } \\
\text { MACHINERY AND } \\
\text { DEVICES. } \\
\text { 2] INSTALLATION ON } \\
\text { CLOSED CABLE } \\
\text { CIRCUITS. }\end{array}$ & $\begin{array}{l}\text { 1] CAN BE USED IN DRY } \\
\text { OR DAMP ROOM. } \\
\text { 2] FOR FIXED } \\
\text { INSTALLATION OF } \\
\text { MACHINERY AND } \\
\text { DEVICES. }\end{array}$ & $\begin{array}{l}\text { 1] WHERE ABSENCE OF } \\
\text { HALOGEN IS REQUIRED. } \\
\text { 2] FOR FIXED } \\
\text { INSTALLATION OF } \\
\text { MACHINERY AND } \\
\text { DEVICES. }\end{array}$ \\
\hline TEMPERATURE RANGE & $\begin{array}{l}\text { 2] FIXED INSTALLATION- } \\
(-40 \mathrm{C}) \text { UP TO }(+80 \mathrm{C})\end{array}$ & $\begin{array}{l}\text { 1] FIXED INSTALLATION - } \\
(-40 \mathrm{C}) \mathrm{TO}+80 \mathrm{C} .\end{array}$ & $\begin{array}{l}\text { 2] FIXED INSTALLATION- } \\
(-25 \mathrm{C}) \text { UP TO }(+80 \mathrm{C})\end{array}$ \\
\hline
\end{tabular}


- PROFINET Type B 4-pair:

Cat $6 \mathrm{~A}$ cables for flexible use

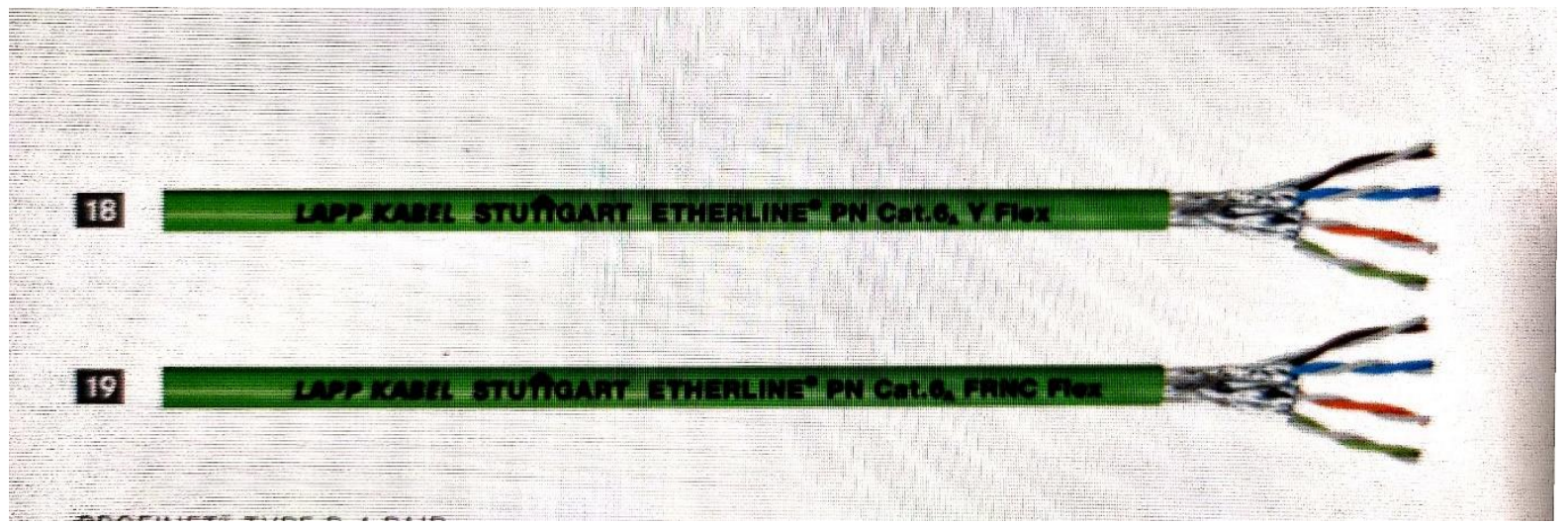

Fig 7

\begin{tabular}{|c|c|c|}
\hline FEATURES & ETHERLINE PN CAT 6 A Y FLEX & ETHERLINE PN CAT 6 A PRNC \\
\hline APPLICATION AREAS & $\begin{array}{l}\text { 1] FOR FIXED INSTALLATION AND } \\
\text { FLEXIBLE BETWEEN MACHINERY } \\
\text { AND PLANTS. } \\
\text { 2] INSTALLATION ON CLOSED } \\
\text { CABLE CONDUITS. }\end{array}$ & $\begin{array}{l}\text { 1] CAN BE USED IN DRY OR DAMP } \\
\text { ROOMS. } \\
\text { 2] WHERE ABSENSE OF HALOGEN } \\
\text { IS REQUIRED. }\end{array}$ \\
\hline PROPERTIES & $\begin{array}{c}\text { 1] FLAME RETARDANT } \\
\text { ACCORDING TO IEC. } \\
\text { 2] OIL RESISTANT ACCORDING TO } \\
\text { UL }\end{array}$ & $\begin{array}{l}\text { 1] FLAME RETARDANT } \\
\text { ACCORDING TO IEC. }\end{array}$ \\
\hline TEMPERATURE RANGE & $\begin{array}{l}\text { FIXED/FLEXIBLE INSTALLATION- } \\
(-10 \mathrm{C}) \text { UP TO }(+70 \mathrm{C})\end{array}$ & $\begin{array}{l}\text { FIXED INSTALLATION- (-25C) TO } \\
\qquad(+80 \mathrm{C})\end{array}$ \\
\hline BENDING RADIUS & $\begin{array}{c}\text { FLEXING- } 15 \times \text { CABLE DIAMETER } \\
\text { FIXED INSTALLATION- } 8 \text { X CABLE } \\
\text { DIAMETER }\end{array}$ & $\begin{array}{c}\text { FLEXING- } 15 x \text { CABLE DIAMETER } \\
\text { FIXED INSTALLATION- 8x CABLE } \\
\text { DIAMETER }\end{array}$ \\
\hline
\end{tabular}

Table 7

- PROFINET type C 4-pair:

Cat 6A cables for special use

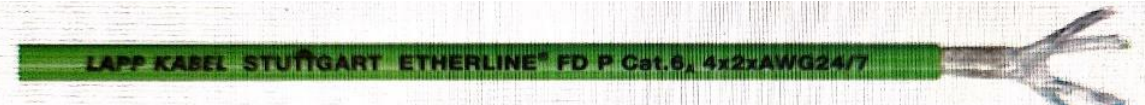

21

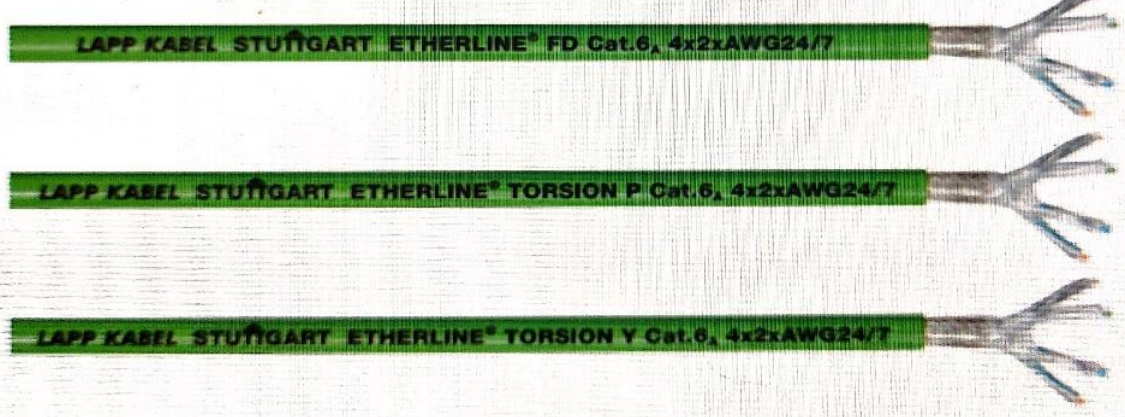

Fig 8 
ISSN No:-2456-2165

\begin{tabular}{|c|c|c|c|}
\hline FEATURES & ETHERLINE FD P CAT 6 A & ETHERLINE FD CAT 6 A & $\begin{array}{l}\text { ETHERLINE TORSION P } \\
\text { CAT A }\end{array}$ \\
\hline APPLICATION AREAS & $\begin{array}{l}\text { 1] WIRING OF } \\
\text { MACHINERY AND } \\
\text { DEVICES. } \\
\text { 2] CAN BE USED IN DRY } \\
\text { OR DAMP ROOM. }\end{array}$ & $\begin{array}{l}\text { 1] CAN BE USED IN DRY } \\
\text { OR DAMP ROOM. } \\
\text { 2] FOR FIXED } \\
\text { INSTALLATION OF } \\
\text { MACHINERY AND } \\
\text { DEVICES. }\end{array}$ & $\begin{array}{l}\text { 1] WHERE ABSENCE OF } \\
\text { HALOGEN IS REQUIRED. } \\
\text { 2] FOR FIXED } \\
\text { INSTALLATION OF } \\
\text { MACHINERY AND } \\
\text { DEVICES. }\end{array}$ \\
\hline PROPERTIES & $\begin{array}{l}\text { 1] OIL RESISTANT } \\
\text { ACCORDING TO UL. } \\
\text { 2] UV RESISTANT } \\
\text { ACCORDING TO UL. }\end{array}$ & $\begin{array}{l}\text { 1] OIL RESISTANT } \\
\text { ACCORDING TO UL. } \\
\text { 2] HALOGEN FREE } \\
\text { ACCORDING TO VDE. }\end{array}$ & $\begin{array}{l}\text { 1] FLAME RETARDANT } \\
\text { ACCORDING TO IEC. } \\
\text { 2] HALOGEN FREE } \\
\text { ACCORDING TO VDE. }\end{array}$ \\
\hline TEMPERATURE RANGE & $\begin{array}{l}\text { 2] FIXED INSTALLATION- } \\
\text { (-40C) UP TO (+80C) }\end{array}$ & $\begin{array}{l}\text { 1] FIXED INSTALLATION - } \\
\text { (-40C) TO +80C. } \\
\text { 2] FLEXING- }(-10 \mathrm{C}) \mathrm{TO} \\
(+70 \mathrm{C})\end{array}$ & $\begin{array}{l}\text { 1] FIXED INSTALLATION- } \\
\text { (-25C) UP TO }(+80 \mathrm{C}) \\
\text { 2] FLEXING- }(-30 \mathrm{C}) \mathrm{TO} \\
(+70 \mathrm{C})\end{array}$ \\
\hline BENDING RADIUS & $\begin{array}{c}\text { FIXED INSTALLATION - } \\
\text { 8x CABLE DIAMETER } \\
\text { FLEXING- 15X CABLE } \\
\text { DIAMETER }\end{array}$ & $\begin{array}{l}\text { FLEXING- 10x CABLE } \\
\text { DIAMETER }\end{array}$ & $\begin{array}{l}\text { FIXED INSTALLATION- 8x } \\
\text { CABLE DIAMETER. } \\
\text { FLEXING- 15x CABLE } \\
\text { DIAMETER }\end{array}$ \\
\hline
\end{tabular}

Table 8

\section{PROFINET Transmission Through Fiber Optic Cable}

On account of correspondence by means of fiber optic links, the information signal that will be moved is changed over from an electrical sign into an optical sign by a functioning segment before move. This optical sign would then be able to be moved along further ways inside a fiber optic link without critical misfortunes. A fiber optic link is a dielectric and straightforward transmission medium.

\section{Diverse Fiber CABLES FOR PROFINET}

- Plastic fiber optic links: -

$\checkmark$ Compliant with IEC 61918 and IEC 61784-5-3

$\checkmark$ Compliant with IEC 60793 Optical Fibers and IEC 60794 Optical Fiber Cables

$\checkmark$ POF - plastic optical fiber

$\checkmark$ Core and sheath produced using plastic

$\checkmark$ Cable length up to $50 \mathrm{~m}$

- Glass strands with plastic external sheath: -

$\checkmark$ Compliant with IEC 61918 and IEC 61784-5-3/PNO particular

$\checkmark$ PCF - plastic cladded fiber

$\checkmark$ Core produced using glass; sheath produced using plastic

$\checkmark$ Core distance across: $200 \mu \mathrm{m}$; sheath breadth: $230 \mu \mathrm{m}$

$\checkmark$ Cable length up to $100 \mathrm{~m}$
- Glass strands: -

$\checkmark$ Compliant with IEC 61918 and IEC 61784-5-3

$\checkmark$ GOF - glass optical fiber

$\checkmark$ Core and sheath produced using glass

$\checkmark$ Initial defensive sheath: $250 \mu \mathrm{m}$ (plastic sheath)

$\checkmark$ Core distance across: $500 \mu \mathrm{m}$ (plastic sheath)

$\checkmark$ Cable length: relies upon fiber type

\section{IWLAN}

Before going into IWLAN let us first investigate WLAN (remote neighbourhood). A WLAN, or remote LAN, is a system that permits gadgets to interface and impart remotely. In contrast to a conventional wired LAN, in which gadgets impart through Ethernet, gadgets chipping away at WLAN convey through WI-FI.

While a WLAN may appear to be unique than a conventional LAN, it works a similar way. New gadgets are regularly included and arranged utilizing DHCP (Dynamic host design convention). They can speak with different gadgets on the system a similar way they would on a wired system. The essential contrast is the manner by which the information is sent. In a LAN, information is sent over physical links in a progression of Ethernet parcels containing. In a WLAN, information is sent remote utilizing one of the IEEE 802.11 conventions.

The most evident bit of breathing space of a WLAN is that gadgets can interface indirectly, getting out the essential for joins. This licenses correspondence without wiring the structure with Ethernet. WLANs are not restricted by the measure of physical ports on the switch and in like way can strengthen bundles or even various 
gadgets. The degree of a WLAN can without a truly surprising stretch be associated by remembering for any occasion one repeater. At last, a WLAN can be effectively invigorated by overriding switches with new structures - a fundamentally not so much troublesome but rather more moderate approach than redesigning old Ethernet joins.

Current Wireless LAN, or IWLAN for short, engages straightforward distant relationship in PROFINET, EtherNet/IP, or Modbus/TCP arranges, and is normally moreover called Wireless Ethernet. IWLAN is depicted by the way that geographically gigantic frameworks can be created with a couple of contraptions. This makes IWLAN perfect for applications, for instance, flexible framework individuals in Automatic Guided Vehicles (AGV) or in crane applications; driverless vehicle structures and appropriation focus transports, electric monorail systems, and working mechanical assembly and systems by methods for tablet and mobile phone. With, prosperity related applications can be constrained by methods for far off. On account of the growing automation of raising devices and transport systems, extending volumes of data must be conveyed. In particular, the necessity for far off data transmission options is extending in the business in light of the constantly growing level of flexibility.

Consistently far off structures are sentenced as too dangerous to even consider evening consider serving needs when uptime is absolutely essential. All things considered, far off advancement has gotten significantly more reliable starting late, to such a degree, that even discrete gathering and vehicle associations trust far off system building in their ordinary structures. This is especially huge as these endeavours incorporate structures that request remarkable precision and unfaltering quality.

Achieving strong distant consideration in a cutting edge circumstance is essentially furthermore testing. Shows, for instance, Parallel Redundancy Protocol (PRP) enable mechanical distant structures to give wiredorchestrate steadfastness. Not solely is mechanical far off advancement reliable, yet it conveys various focal points to your undertakings. It can help increase the flexibility and advantage of methodology and delegates. Far off is consistently thought of as an approach to cost-feasibly and securely partner with far off districts and it does that well in fact.

Not exclusively is modern remote innovation solid, however it carries numerous advantages to tasks. Remote is regularly thought of as a way to cost-successfully and safely interface with distant locales and it does that well indeed. Be that as it may, there are different business advantages of sending modern remote innovation including:

- Remote labourers: - It isn't permitting staff to work offsite, telecommuters use a remote framework to work somewhere else on the assembling floor, while keeping up access to all the data important to screen and control machines and procedures.
- Real-time information assortment: - Adding remote sensors can be a financially savvy and negligibly problematic approach to accumulate extra operational information from a current framework. This advantage demonstrates particularly accommodating in applications like quality control or representative wellbeing, where access to information is required quicker than at any other time.

- Improved diagnostics: - With access to more noteworthy measures of all the more opportune information, producing issues can be dodged before they occur. Business profits by upgraded effectiveness, decreased vacation and, at last, expanded gainfulness.

Let us look consider the example of Siemens to appreciate IWLAN better. Siemens has made submitted Industrial Wireless LAN (WLAN) things with phenomenal additional abilities to satisfy the specific needs of Wi-Fi in industry. These are particularly significant for applications in automation, for example in vehicle gathering, transportation and coordination's, and the oil and gas industry. They have made exceptional iFeatures for use in mechanical conditions that are engaged by KEY-PLUGs or CLPs inserted into the devices. These sharp additional limits can be started as programming moreover thusly on various IWLAN Access Points and Client Modules. These additional limits are fitting for all endeavours and a wide scope of usage. The going with typical occurrences of usage offer more point by point information.

- IWLAN in logistics: - Logistics need low-upkeep, safe Industrial Wireless LAN (IWLAN) arrangements that can be utilized inside and out - for instance, to run stockpiling and recovery frameworks, transport frameworks or Automated Guided Vehicles (AGV). All frameworks as a matter of first importance must be ok for individuals, and proficient to utilize. With assorted applications to be done there is wide scope of choices accessible from Siemens.

An IWLAN arrangement blending a SCALANCE W Access Point and a Client Module makes it simple and safe to control stockpiling and recovery frameworks. AGVs assume a significant job in plant logistics anyplace transport undertakings emerge underway, for example, in conveying materials holders to workstations, or in warehousing completed items.

KEY ADVANTAGES: -

$\checkmark$ Real-time communication especially for mobile clients within a field

$\checkmark$ Safe industrial control in Automated Guided Vehicles

$\checkmark$ Flexibility

$\checkmark$ Very fast roaming times for uninterrupted communication

$\checkmark$ Life cycle: more than ten years

$\checkmark$ A solution usable across sectors for a vast range of applications 
- iPCF- MC for wireless communication in logistics applications: - Controllers and I/O systems in the PROFINET environment and EtherNet/ IP applications cannot communicate reliably with one another via the IEEE 802.11 WLAN standard, because they are not deterministic. Here the iPCF (Industrial Point Coordination Function) offers a solution for guided applications. For freely moving network, iPCF-MC comes into play.

- IWLAN in the automotive industry: - Efficient production is essential in Automotive manufacturing and is among the most profitable and fastest-moving industries worldwide. The huge production pressure makes it mandatory to avoid plant downtimes that can result in significant losses. Production in the automotive industry is also strongly influenced by automation. Wireless data communication with Industrial Wireless LAN (IWLAN) plays an important role in many areas of the automotive industry in supporting reliable and safe operations.

KEY ADVANTAGES: -

$\checkmark$ Safe, wireless communication for high performance and personal safety

$\checkmark$ Cost reduction

$\checkmark$ Very fast, uninterruptible communications $<50 \mathrm{~ms}$.

$\checkmark$ Safe emergency stop function for automation components

$\checkmark$ Connection to existing production networks is based on standards.

\section{$>$ Data transmission: -}

The Siemens Industrial Wireless LAN with RCoax link can exhibit its focal points especially with versatile gatherings, which move along a predefined course in radioin fact testing conditions. A characterized and constrained radio field is conformed to the link, which runs accurately in the territory it is required.

\section{Adaptable application choice: -}

Regardless of whether open or encased conductor lines, slip ring congregations or quite certain application conditions, with the IWLAN framework and the RCoax cracked feeders, we give you an exceptionally adaptable framework.

Favourable position initially: -

- Highest level of dependability regarding controlled and characterized radio field

- Non-contact information transmission and in this way, low-support.

- Flexible application alternatives

- Cost reserve funds because of replacement of conductor lines and following links.

\section{SCALANCE W Devices: -}

- Supported frequencies: - Two frequencies are used for wireless networks based on 802.11n and 802.11ac standards. They are $2.4 \mathrm{GHz}$ and $5 \mathrm{GHz}$.

- Data transmission rate: - SCALANCE W components can handle any data rates. From $150 \mathrm{Mbit} / \mathrm{s}, 300 \mathrm{Mbit} / \mathrm{s}$ and $450 \mathrm{Mbit} / \mathrm{s}$, right up to $1733 \mathrm{Mbit} / \mathrm{s}$ for wide data transmission.

- Combined with antenna portfolio: - from omnidirectional antennas and directional antennas to RCoax cables, SCALANCE W components can be combined with suitable antennas.

Range of SCALANCE W components is suitable for use in any application: -

- For use in the control cabinet: - SCALANCE W760 Access Points and SCALANCE W720 Client Modules are the choice for wireless communication from the control cabinet, especially in tight spaces that are difficult to access. The SIMATIC design means that automation components such as the distributed I/O SIMATIC ET 200SP can be incorporated seamlessly in IWLAN network.

- For use inside and outside the control cabinet: SCALANCE W770 Access Points and SCALANCE W730 Client Modules are the solution for more demanding applications. With data rates up to 300 $\mathrm{Mbit} / \mathrm{s}$, it is possible to cover larger wireless ranges. SCALANCE W774 Access Points and W734 Client Modules with the SIMATIC design are the perfect way of ensuring wireless communication between the control system SIMATIC S7-1500 and a SIMATIC ET 200MP. With their IP65 protection class, SCALANCE W778 Access Points and W738 Client Modules are also ideally suited to wireless data transmission in harsh environments.

- For use in harsh environments: - SCALANCE W780 Access Points and SCALANCE W740 Client Modules are reliable, powerful and extremely robust, they are ideal for handling most demanding tasks. Gadgets with IP30 assurance class are reasonable for use in the control bureau, though IP65 gadgets are ideal for use outside the control bureau and under unforgiving natural conditions.

- For extremely high bandwidths: - With gigabit data rates of up to $1733 \mathrm{Mbit} / \mathrm{s}$, the WLAN standard IEEE 802.11ac Wave 2 enables the implementation of wireless applications with high bandwidths. The SCALANCE W-1700 supports radio transmission in both industrial and moderate environments. Typical areas of application include networks with high user density and high-performance video transmission. The SCALANCE W1788 Access Points with IP65 protection class are especially suitable for use in harsh industrial environments. In moderate environments, the SCALANCE W1750D Direct Access Points can be used to configure and centrally manage wireless networks with up to 64 Access Points. 
ANTENNAS: - Signal reception is all-important in WLAN networks. By using the wireless network correctly and the appropriate components, it is possible to avoid fault from the outset, thus considerably reducing the commissioning time. Some typical antennas from siemens include: -

$\checkmark$ Omnidirectional antennas to cover a large wireless field in all directions.

$\checkmark$ Directional antennas for a directional wireless field.

$\checkmark$ Sector or wide-angle antennas for large wireless fields.

$\checkmark$ Special antennas for RCoax applications.

RCoax radiating cables: - If conventional antennas are not suitable for a particular communication requirement, RCoax may be the solution. Coaxial cables are robust and easy to install, and they are especially suited for crane applications, elevators or rail vehicles. With RCoax radiating cables, usage of Wireless LAN can take place without any of the restrictions: the RCoax radiating cable acts as an antenna for SCALANCE W Access Points. The cable is laid along the route used by the relevant transmitters/receivers and provides a guaranteed and reliable wireless connection due to its special radiation properties.

PLUGs for network components: - Replacement of SCALANCE W components can be done quickly and safely in the event of faults.

C-PLUG: - Automatically backs up configuration data and firmware so that the SCALANCE W-700 can easily be replaced in the event of faults.

KEY-PLUG: Includes all C-PLUG functions and activates special additional functions for selected SCALANCE W700 devices.

CLP: In various versions, the CLP stores the configuration data for the SCALANCE W-1700 family.

\section{IFeatures at a glance: -}

$\checkmark$ iPCF (industrial Point Coordination Function): ensures required deterministic behaviour and fast roaming in PROFINET and EtherNet/IP applications, including for gross data rates up to $54 \mathrm{Mbit} / \mathrm{s}$.

$\checkmark$ IPCF-MC (iPCF Management Channel): ensures required deterministic behaviour and real-time communication in applications with free-moving clients.

$\checkmark$ IPRP (industrial Parallel Redundancy Protocol): ensures redundant, reliable WLAN communication.

$\checkmark$ IREF (industrial Range Extension Function): makes it possible to cover longer distances with a single Access Point.

\section{BENEFITS and POSSIBILITIES of SOLUTION WITH} IWLAN

- Cable and Connection: - Wireless connections are ideal in cases where laying cables is a complex process. SCALANCE-W from siemens helps provide total flexibility and safe communication at all time without wired connection.
- Secured Communication: - Along with data safety personal safety is also a priority in production and transportation processes. Security standards are maintained by following protocols such as (IEEE802.1X) and encryption. Implementation of Profinet and Profisafe along with stop function from WLAN to assure safety for employees.

- Timing of Data Transmission: - SCALANCE W devices and iFeatures help in quick transmission of data units from Point A to B.

- Reliable Communication: - Along with quick and reliable communication another must point is that there should be no loss of information. SCALANCE W devices identify and fix if error occurs.

- Robust and flexible: - SCALANCE W devices are IP65 approved with ability to sustain in harsh environmental conditions.

- Easy configuration: - Usage of siemens network management system SINEC NMS establishes wireless network with minimal effort. Also, additional components can be added with any problem.

Let us investigate the instance of BELDEN which makes such IWLAN. BELDEN's contributions which are for the sake of its image HIRSCHMANN are somewhat extraordinary to different organizations in this field. As per them a ton of organizations are looking at going remote. They feel the worry about security, the worry about unwavering quality, the worry about carrying obscure innovation into the modern condition. In all actuality, the present modern remote arrangements can change your business. There can be increment in organize security and diminish vacation. There can be combination of remote and wired parts to improve generally speaking framework the board and productivity. There is an opportunities for futureverification of the system to guarantee that the organization is prepared for circumstances rising up out of the "Modern Internet of Things" pattern. Here are a portion of their contributions.

\section{- OpenBAT Wireless Platform}

The OpenBAT family involves the BAT-R (IP30) and BAT-F (IP65/67) arrangement of WLAN passageways. Both OpenBAT arrangement have altogether new equipment and work with the most remarkable working framework HiLCOS. The passageways and customers in the new OpenBAT family can be mounted on BAT-R or introduced on dividers or poles in indoor and outside BATF territories. They are Available with or without conformal covering; the gadgets have a working temperature scope of $0^{\circ} \mathrm{C}$ to $+60^{\circ} \mathrm{C}$ or $-40^{\circ} \mathrm{C}$ to $+70^{\circ} \mathrm{C}$. All adaptations bolster the IEEE 802.11n transmission standard, with PROFINET, EtherNet/IP, Public Spot and VPN Gateway as choices. Key focuses: -

$\checkmark$ A exceptional stage idea that permits customized arrangements with an ideal value execution proportion.

$\checkmark$ It is an Innovative remote innovation that ensures most extreme WLAN accessibility.

$\checkmark$ Integrated ESD insurance guarantees high unwavering quality and an incredibly long operational lifetime for the passageways. 


\section{- BAT450-F Industrial Wireless LAN Access Points}

The BAT450-F mechanical remote LAN passage family includes numerous interface arrangements and association choices, a rough, minimal plan and work with the most impressive working framework HiLCOS. The BAT450-F family's WLAN passages highlight an amazingly rough, minimal plan for modern needs and can be altered to help an assortment of remote and wired associations.

These WLAN gadgets can be utilized in blend with the BAT regulators as Access Client or Access Point. Key Points: -

$\checkmark$ Reliable and can be conveyed in cruel situations and mounting regions because of tough, reduced plan

$\checkmark$ Ensure greatest system accessibility and information security across remote associations with secure HiLCOS working programming

$\checkmark$ Increase effectiveness and strength in rail applications with alternative of direct $110 \mathrm{~V}$ DC power gracefully

- BAT867-R Industrial Wireless Access Points Aides in Transmitting information rapidly up to 867 megabits for each second (Mbps), with the BAT867-R mechanical remote passage. This gadget bolsters rapid IEEE 802.11ac information rates, making it the quickest remote gadget in Belden's portfolio. Its tough plan, minimal size and select list of capabilities assist applications with amplifying productivity and execution. The BAT867-R is perfect for modern settings where space and spending plans are constrained, for example, discrete mechanization and machine building settings. By just including the basic interfaces, Hirschmann offers a financially savvy, fast arrangement. Key focuses: - • Fast information speeds Enables fast information transmission up to $867 \mathrm{Mbps}$ with an IEEE 802.11ac radio module.

$\checkmark$ Industrial plan - Complies with the difficult necessities and endorsements of mechanical markets, the gadget likewise can withstand signal obstruction, vibrations, EMC and that's only the tip of the iceberg.

$\checkmark$ Cost-successful Solution - Only compensation for the highlights required by normal modern WLAN applications to lessen the general expenses - one radio, one Ethernet port, one force gracefully. It can be utilized as a passageway, customer, switch or extension.

$\checkmark$ Reliable remote network - Flexibility by observing and working machines from remote tablets or cell phones. Additionally improves warehousing productivity by giving remote availability to moving vehicles, for example, forklifts and computerized guided vehicles (AGVs).

\section{- BAT-C2 WLAN Client and Access Point}

Hirschman's BAT-C2 WLAN Client and Access Point gives uplifted execution and cost-proficiency contrasted with progressively robotized modern condition. The smaller plan considers simple mix into present day $\mathrm{AGVs}$ and robots for modern applications. Striking Key Points: - $\checkmark$ 802.11ac WLAN Client with quick wandering innovation, WLAN Access Point for machine building and far off upkeep.

$\checkmark$ Supports synchronous Access Point/Client work on a similar channel, Lightweight for most extreme undertaking adaptability.

$\checkmark$ Configurable establishment through similarity with outsider gadgets and programmed Access Point control through neighbourhood Wi-Fi.

$\checkmark$ Robust, IP65-appraised plastic lodging with a working temperature scope of $-40^{\circ} \mathrm{C}$ to $+70^{\circ} \mathrm{C}$.

$\checkmark$ Now we look into the IWLAN offered by PHEONIX CONTACT. According to them their Industrial WLAN offers the following features: -

$\checkmark$ Reliable wireless communication, thanks to the MIMO antenna technology and data transmission rates of up to 300 Mbps.

$\checkmark$ Suitable for safety applications, thanks to functionally safe data transmission via Safety Bridge or PROFIsafe.

$\checkmark$ Flexible in application: optimized for industrial protocols such as Profinet, EtherNet/IP, Modbus-TCP and others.

$\checkmark$ High-speed reliable roaming for mobile applications.

We look into some of their offerings:

- WLAN 5110

WLAN 5110 is the compact WLAN module for control cabinets and control boxes. External antenna connections allow flexible use of antennas to match the respective application. Thus, a broad range of directional antennas can be installed, whether unidirectional long-range antennas, omnidirectional antennas for covering large areas, or leakage-cable antennas for track-guided electric monorail systems.

$\checkmark$ Compact design - suitable for control boxes in the field.

$\checkmark$ Cluster management technology for the central configuration of all Access Points in a WLANinfrastructure network.

$\checkmark$ Two external antenna connections for the flexible use of antennas.

$\checkmark$ Comprehensive user-friendly functions simplify commissioning and maintenance.

- WLAN 1100 and WLAN 2100

WLAN 1100 and WLAN 2100 are the cost-effective WLAN solutions with integrated antennas and wireless module in a single device. The wireless module is mounted easily onto machines or automated guided vehicle systems (AGVs) via single-hole mounting.

$\checkmark$ Quick and easy full WLAN reception at all times.

$\checkmark$ Two coordinated unique reception apparatuses for solid remote correspondence in mechanical conditions.

$\checkmark$ Fast, simple establishment, because of single-gap mounting

$\checkmark$ Extremely powerful lodging, sway safe as per IK08

$\checkmark$ Extended temperature range and insurance class IP66/IP68 for remote correspondence in unforgiving situations if there should be an occurrence of WLAN 2100 in particular. 


\section{- WLAN EPA}

The Ethernet port enables WLAN capability in industrial automation devices with Ethernet connection quickly and easily. The IP65 solution is installed directly in the field and connected to the automation device via an M12 Ethernet cable. $\checkmark$ Compact IP65 module with integrated antenna.

$\checkmark$ M12 connections for Ethernet and power.

$\checkmark$ Easy installation in the field.

$\checkmark$ Easy configuration, thanks to the Mode button.

$\checkmark$ Maximum data throughput: 20 Mbps.

\begin{tabular}{|c|c|c|c|}
\hline & WLAN 5110 & WLAN 1100 & WLAN EPA-2 \\
\hline MOUNTING & IN THE CONTROL & ON THE CONTROL & ON THE CONTROL \\
& CABINET & CABINET & IEEE 802.11 \\
& IEEE 802.11 & IEEE 802.11 & 2.4 GHZ \\
\hline FREQUENCY BAND AND & 2.4 GHZ & $2.4 \mathrm{GHZ}$ & 54 MBPS \\
\hline WLAN STANDARD & 300 MBPS & 300 MBPS & LESS THAN 20 MBPS \\
\hline MAX DATA RATE & LESS THAN 90 MBPS & LESS THAN 60 MBPS & 18 DBM \\
\hline MHAX DATA & 18 DBM & 20 DBM & 1 \\
\hline MAX TRANSFER POWER & 1 TO 2 & 2 & \\
\hline NO OF ANTENNA & & & \\
\hline
\end{tabular}

Table 9

\section{CONCLUSION}

PLC language has built up the control framework, and it has become the most valuable language. They gracefully uphold engineers with what they need and they keep administrators shielded from dangerous machines. The capability of programmable rationale regulators in controlling frameworks is practically boundless. Programmable L controls have taken care of and upheld control frameworks from various perspectives. Most cycle PCs used in manufacturing plants with people have a bigger number of favourable circumstances than detriments as a protected framework when managing complex cycle. PLCs have demonstrated to be a compelling and accommodating instrument in numerous enterprises previously. With their numerous points of interest, they will keep on being valuable later on also. With the start of the advanced businesses, the architects required frameworks to assist them with quickening creation and to get high calibre easily. Electronic frameworks as sensors and switches were developed to screen and control fabricating and decrease work and creation mistakes. Switches and sensors were expected to supplement programming and equipment and to accelerate the examination of information and acquire the outcomes to help the architects in handling steps. The main framework and programming utilized around there was the SCADA framework. Notwithstanding, this framework was intricate and couldn't be connected with other checking frameworks. Thus, they designed the PLC, which thus encouraged the way toward programming. Likewise, it contained numerous prospects including its capacity to associate effectively with different frameworks underway lines to aid the advancement of the creation cycle. PLC, which has a basic influence during the time spent computerization and control, is one of the most significant frameworks in numerous manufacturing plant creation lines, and it has a bigger number of highlights than different frameworks.

\section{REFERENCES}

[1]. PLC: - SNTI CAPABILITY DEVELOPMENT JAMSHEDPUR

[2]. RS485- B\&B ELECTRONICS

[3]. PROFINET: - LAPP KABEL

[4]. IWLAN: - SIEMENS AG, BELDEN, PHEONIX CONTACT 